See discussions, stats, and author profiles for this publication at: https://www.researchgate.net/publication/303889538

\title{
Projected climate change impacts on upland heaths in Ireland
}

Article in Climate Research · July 2016

DOI: $10.3354 /$ cro1408

CITATIONS

6 authors, including:

John Coll

National University of Ireland, Maynooth

39 PUBLICATIONS 201 CITATIONS

SEE PROFILE

Micheline Sheehy Skeffington

National University of Ireland, Galway

70 PUBLICATIONS 636 CITATIONS

SEE PROFILE
READS

337

David Bourke

Liverpool John Moores University

39 PUBLICATIONS 299 CITATIONS

SEE PROFILE

M. Gormally

National University of Ireland, Galway

13 PUBLICATIONS 225 CITATIONS

SEE PROFILE

Some of the authors of this publication are also working on these related projects:

A Special Report on Emissions Scenarios 'SRES' for Ireland View project

Eutrophication from Agricultural Sources View project 
Author note: this is a 'near final' version. Copyright restrictions prevent public posting of the 'Climate Research' published MS.

\title{
Projected climate change impacts on upland heaths in Ireland
}

\author{
John Coll ${ }^{1}{ }^{1}$, David Bourke ${ }^{2,3}$, Rory L. Hodd ${ }^{4}$, Micheline Sheehy Skeffington ${ }^{4}$, \\ Michael Gormally ${ }^{3}$, John Sweeney ${ }^{1}$ \\ ${ }^{1}$ Department of Geography, Maynooth University, Maynooth, Co Kildare, Ireland \\ ${ }^{2}$ School of Natural Sciences, Liverpool John Moores University, Liverpool L3 3AF, \\ UK
${ }^{3}$ Applied Ecology Unit, Centre for Environmental Science, School of Natural Sciences, National University of Ireland Galway, Galway, Ireland
${ }^{4}$ Plant Ecology Research Unit, National University of Ireland Galway, Galway, Ireland \\ *Corresponding author: john.coll@nuim.ie
}

\begin{abstract}
Heathland habitats in Ireland occur primarily in an oceanic setting which is strongly influenced by changes in the climate. Because of the oceanic environment, Ireland has a high proportion of the northern Atlantic wet heaths and alpine and boreal heaths of high conservation value within Europe. Future climate change is widely expected to place additional pressure on these systems. Seven bioclimatic envelope modelling techniques implemented in the BIOMOD modelling framework were used to model wet heath and alpine and boreal heath distributions in Ireland. The 1961-1990 baseline models closely matched the observed distribution and emphasise the strong dependency on climate. Mean winter precipitation, mean winter temperature and elevation were found to be important model components. The fitted model's discrimination ability was assessed using the area under the curve; a receiver operating characteristic plot; the true skill statistic; and Cohen's kappa. A BIOMOD ensemble prediction from all the models was used to project changes based on a climate change scenario for 2031-2060 dynamically downscaled from the Hadley Centre HadCM3-Q16 global climate model. The climate change projections for the individual models change markedly from the consistent baseline predictions. Although the consensus models project gains in climate space for both habitats in other parts of the country, new habitat formation in these areas is unlikely, as current (and hence near-future) land use and other conditions are not likely to favour expansion.
\end{abstract}

KEY WORDS: Wet heaths - Alpine heaths - Boreal heaths - Climate change · Bioclimatic envelope models $\cdot$ BIOMOD $\cdot$ Climate space 


\section{INTRODUCTION}

\subsection{Conservation importance of maritime uplands}

Mountainous regions contain a high proportion of the world's biodiversity (Orme et al. 2005), including a range of species with unique adaptations and high extinction risk (Ricketts et al. 2005). Future climate change is widely thought to have the potential to exacerbate both the pace and the amplitude of these extinctions (Bellard et al. 2014). It is anticipated that an amplification of the elevation-dependent warming already detected will accelerate the rate of change in mountain ecosystems (Pepin et al. 2015). However, projections from different climate models vary markedly, and local processes for upland regions are poorly captured (Coll 2010, Coll et al. 2010); hence, more localised modelling studies are required to inform management decisions. The oceanic upland habitats of Ireland and Scotland and their associated oceanic species and vegetation are of high conservation value but are also considered vulnerable to climate change (Coll et al. 2010, 2014a, Hodd \& Sheehy Skeffington 2011a). Heathlands are typically communities that flourish in oceanic climates both at altitudes above the tree line and at sea level (Crawford 2008). A fuller account of species assemblages for Irish montane heaths is provided in Hodd \& Sheehy Skeffington (2011a), and a review of drivers of change for heaths in Fagúndez (2013). Heath communities have a restricted global distribution and support many species of limited distribution in Europe; consequently, Ireland has a special responsibility under the European Union (EU) Habitats Directive (Council Directive 92/43/EEC) to conserve them (Holden et al. 2007). This study focuses on 2 habitats listed in Annex I of the EU Habitats Directive, the 4010 northern Atlantic wet heaths and 4060 alpine and boreal heaths, as defined in the Habitats Interpretation Manual (EU 2013).

\subsection{Bioclimatic envelope modelling}

Various modelling approaches have been used to convert species distributions into predictive maps, and bioclimatic envelope models (BEMs) - which can be considered as a variant of niche-based or species distribution models (Guisan \& Thuiller 2005, Heikkinen et al. 2006) — are widely used. However, confidence in the predictive power of BEMs is compromised by conceptual, biotic and algorithm flaws. These include unrealistic model assumptions (Schroder \& Seppelt 2006, Dormann 2007), uncertainty regarding variable selection (Austin \& Van Niel 2011), and lack of agreement over the classification of basic concepts (Segurado \& Araújo 2004, Araújo \& Guisan 2006, Austin 2007). Hence, there is ongoing debate concerning the strengths and limitations of the models and potential areas for their improvement (Araújo \& Peterson 2012).

Arising from this debate, the use of consensus methods is popular on the basis that they decrease the predictive uncertainty of single models by combining their predictions (Marmion et al. 2009b, Grenouillet et al. 2011) and provide the advantage of combining forecasts to give a probability distribution per pixel as opposed to a single value (Thuiller 2014). Therefore, the ensemble prediction provided by the BIOMOD modelling framework (Thuiller 2003, Thuiller et al. 2009) is particularly useful in reducing the uncertainty associated with individual model types. 
The use of BEMs for habitats is novel, and only a limited number of studies have applied these methods to landforms and habitats (e.g. Fronzek et al. 2006, Parviainen \& Luoto 2007). However, based on work undertaken for UK (Clark et al. 2010) and Irish peatlands (Coll et al. 2011, 2013, 2016), climate is known to exert a strong control on these upland ecosystems and underpins the decision to apply BEMs to the heath habitats here.

\subsection{0 northern Atlantic wet heaths}

Northern Atlantic wet heaths in Ireland result from several thousands of years of a wet, oceanic climate that has resulted in the formation of shallow peat, even on montane slopes, often in a complex mosaic with blanket bog and dry heath. Historical grazing by stock in varying intensities and/or burning regimes are also contributing factors to plant community variation. The vegetation is typically dominated, to varying degrees, by a mix of Calluna heath, Racomitrium moss heath, grassland and blanket bog. Stands of wet heath occur on acidic, nutrient-poor substrates where rainfall maintains them in a permanently wet condition but where factors such as slope prevent deep peats from forming. Therefore, at all altitudes in a maritime setting, heath development is the result of interactions between a cool, wet, Atlantic climate and drainage extent.

The European distribution of wet heath is restricted to the areas of oceanic and on the periphery of the eastern North Atlantic region below the alpine zone. In Ireland and the UK, wet heath is usually found in the wetter climates of the north and west (Hampton 2008) and in eastern areas is restricted to uplands associated with higher rainfall. Here, the oceanic climate also results in a lower tree line than in more continental uplands (Crawford 2005). Habitat 4010 wet heath has been defined in an Irish context as a highly variable habitat, usually dominated by the graminoid Molinia caerulea or sedge (Cyperaceae) species, with a sparse cover of dwarf shrubs (Perrin et al. 2014). Intermediate in many regards between dry heath and blanket bog, the habitat generally occurs on gently sloping ground on shallow or intermediate $(<1 \mathrm{~m})$ peat depths (Perrin et al. 2014). The habitat is widespread in the west but is absent from large parts of the northern Midlands, as conditions are not suitable for wet heath (Fig 1a).

The dominant and characteristic plant species of wet heath are not considered sensitive to climate change (Berry et al. 2005) and may even benefit from the predicted milder, wetter winters and drier summers (Berry et al. 2002). However, many European heathland areas face an uncertain future due to a wide range of other pressures and drivers (Fagúndez 2013). The response to climate change will be determined by how shifts in precipitation, air temperature, humidity and wind speed affect seasonal and inter-annual soil moisture balances. Higher temperatures are expected to result in increased biomass production in heath communities providing that soil moisture changes do not lead to an increased drying of soils (Peñuelas et al. 2004).

Changes in relation to climate change are uncertain, but amid various contradictory interpretations, there are indications that wet heath will not be adversely affected and that an increase in annual rainfall totals may encourage the development of wet heath at the expense of dry heath (Hampton 2008). Warmer summers and wetter winters could also indirectly affect upland heaths through their impact on peat soils and the potential release of carbon locked up in these soils (Kirschbaum 2000). 
Winter re-wetting may potentially exacerbate erosion and lead to a decline in the quality and extent of the habitat.

\subsection{0 alpine and boreal heaths}

Alpine and boreal heath habitats are found in mountain areas across Europe and, in continental mountain ranges, are usually located between the tree line and the grassland communities. Associated with shallow mineral soils, the heaths are also found on areas of loose rock and coarse sediment on mountaintops and ridges (Zaghi 2008). Alpine heaths develop above the natural altitudinal tree line, whereas boreal heaths develop below the tree line in gaps among scrubby high-altitude woodland, although this distinction is not clear in oceanic areas (Hodd \& Sheehy Skeffington 2011a).

The habitat in Ireland is one where vegetation cover is rarely complete but normally exceeds 50\% (Fossitt 2000). Alpine and boreal heath in good condition is typically dominated by a range of low-growing, wind-clipped dwarf shrubs, but in oceanic areas, dwarf shrub cover is often low, with the moss Racomitrium lanuginosum becoming dominant (Hodd \& Sheehy Skeffington 2011a, Perrin et al. 2014). Irish alpine and boreal heath is confined largely to the mountain areas, with a limited distribution in Northern Ireland (Fig. 1b). Alpine and boreal heath has been highlighted as sensitive to a changing climate (Zaghi 2008), and climate change is projected to adversely affect arctic-montane plants in Ireland generally (Coll et al. 2013, Hodd et al. 2014).

Re-survey data in the Scottish Highlands show that a loss of specialised species has already taken place in some dwarf shrub heaths, grasslands and alpine heaths (Ross et al. 2012, Ross 2015). Model-based results from Scotland also indicate major shifts in seasonal isotherms associated with upland zones (Coll 2007, Coll et al. 2010). However, while some tree encroachment into the sub-alpine zone is possible, this is unlikely to occur since tree lines in Ireland are significantly affected by wind (Hodd \& Sheehy Skeffington 2011a). Thus, the interaction between local topography and possible wind field changes is likely to remain a more significant local control for Ireland, while future management regimes, particularly grazing levels, will also be important.

Although suitable climatic conditions are likely to persist for some heath types in Ireland, details of the effects of a changing climate on distributions are currently unclear. Any climatic change will be exacerbated on the mountain summits and on habitats currently at the edge of their natural range (Coll et al. 2010). It is likely that more sensitive species will be more vulnerable (Coll et al. 2013) and that the small area and low altitude of Ireland's mountains reduce species' options to track areas of suitable climate (Hodd et al. 2014).

The primary aim of this study was to model the impacts of climate change for wet heath and alpine and boreal heath Annex I habitats for the island of Ireland using climate and elevation variables as predictors in a BEM framework. In addition, a consensus model based on the averaged spatial probabilities for the model categories selected was used to project changes in future climate space for both habitat types. Insofar as we are aware, this is the first application of a BEM ensemble modelling framework to heathland habitat data, and the approach with some refinements could be used to inform future management. 


\section{MATERIALS AND METHODS}

\subsection{Study area}

The study area is the whole island of Ireland and covers ca. $84421 \mathrm{~km}^{2}$ on the Atlantic margin of northwestern Europe, between the latitudes of ca. $51^{\circ} 00^{\prime}$ and $56^{\circ}$ $00^{\prime} \mathrm{N}$ (Fig. 1a). Altitudes range up to $1040 \mathrm{~m}$ a.s.l. (Corrán Tuathail, County Kerry). Much of the island is lowland, with mountain areas mainly being near the coast and with a characteristic temperate oceanic climate. Mean annual temperature (averaged over 1961-1990) is highest on the southwestern coast $\left(10.4^{\circ} \mathrm{C}\right)$ and lowest inland $\left(8.8^{\circ} \mathrm{C}\right)$. On average, annual precipitation ranges from 750 to $1000 \mathrm{~mm} \mathrm{yr}^{-1}$ in the drier eastern half of the country and is over $3000 \mathrm{~mm} \mathrm{yr}^{-1}$ in parts of the western mountains (Rohan 1986).

\subsection{Data}

Distribution data for the habitats was provided by the Irish National Parks and Wildlife Service (NPWS). The data are based on a combination of habitat and species distribution maps on a $10 \times 10 \mathrm{~km}$ grid supported by NPWS surveys (NPWS 2008). These data were complemented by data for Northern Ireland Annex I reporting from the Joint Nature Conservancy Council database (JNCC 2007) (see Fig. 1a,b).

A quality-controlled set of 1961-1990 baseline climate data was used to test and construct the BEMs for the baseline period. These $10 \times 10 \mathrm{~km}$ resolution data are derived from observed monthly climate data for 560 precipitation stations and 70 temperature stations interpolated using a polynomial regression method with an inbuilt adjustment for elevation (Sweeney \& Fealy 2003).

Met Éireann (the Irish Meteorological Service) supplied HadCM3-Q16 global climate model $(\mathrm{GCM})$ data dynamically downscaled to a $14 \times 14 \mathrm{~km}$ grid resolution via the regional atmospheric model RCA3 (McGrath \& Lynch 2008). The bioclimatic envelope modelling here is based on data for an A1B scenario from the above GCM and regional climate model (RCM) combination. The A1B scenario projects a rise in annual temperature of 1.3 to $1.8^{\circ} \mathrm{C}$, a decrease in summer precipitation by 5 to $10 \%$ and an increase in autumn and winter precipitation by 5 to $10 \%$ by 2021-2060 relative to the 1961-1990 baseline (McGrath \& Lynch 2008). The projected warming is greatest in the south and east of the country, whereas there is no clear regional trend for precipitation (McGrath \& Lynch 2008). The HadCM3-Q16 simulation of winter rainfall is in the intermediate to low range among the ENSEMBLES RCMs (Jacob et al. 2008).

RCA3 simulated climate data for 1961-1990 and 2031-2060 were converted to daily and monthly mean values for temperature and precipitation variables, and $\mathrm{R}$ based routines (R Development Core Team 2014) were used to re-interpolate these data to the $10 \times 10 \mathrm{~km}$ modelling grid. The climate change signal derived with respect to the RCA3 simulated 1961-1990 baseline for each $10 \times 10 \mathrm{~km}$ grid cell was then applied to the observed data for the variables of interest.

\subsection{Derivation of explanatory variables}

Both the baseline climate data and the climate change signal data were converted to monthly and seasonal values for use in the BEMs. In addition to 8 climate variables, 4 variables for topography were also included (Table 1). The data 
ranges for the baseline climate variables are also provided alongside those for the A1B climate change scenario data used (Table S1 in the Supplement, available at www.int-res.com/articles/suppl/c069p177_supp.pdf). The range of candidate explanatory variables evaluated also overlap to some extent with those reported elsewhere (e.g. Marmion et al. 2009a, Engler et al. 2011, Coll et al. 2014).

Mean elevation for each $10 \times 10 \mathrm{~km}$ grid cell (ArcGIS 10.2 software) was derived from a digital elevation model (GTOPO30) with a horizontal grid spacing of $30 \operatorname{arc~s}(\sim 1 \mathrm{~km})$, and the range was calculated as highest minus lowest elevation in the focal cell. The data were then referenced to the climatic datasets.

\subsection{Modelling framework}

We implemented a selection of 7 from the 9 available modelling approaches in BIOMOD in this study. The techniques included a mixture of regression methods: generalised linear models (GLMs) and generalised additive models (GAMs); the machine-learning methods artificial neural network (ANN), random forest (RF) and generalised boosting method (GBM); and 2 classification methods, classification tree analysis (CTA) and flexible discriminant analysis (FDA).

A further objective in the model building process was to screen out collinearity in the covariates selected for the baseline models. This recognises that multiple regression-based approaches can be hampered by multicollinearity among predictors (Heikkinen et al. 2006, Dormann et al. 2013). BIOMOD can usefully specify non-linear terms for GLM in particular, thereby opening up many more candidate covariate possibilities. However, there is no screen for collinearity among predictors in BIOMOD per se. Therefore, a combination of correlation matrices and principal components analysis (PCA) was used to screen the available covariates beforehand, and any collinear terms were excluded from the final covariates used. There was also a posteriori knowledge of where collinearity in the covariates was likely based on previous work (Coll et al. 2011, 2013, 2014).

For all 7 wet heath models, the variables used were annual temperature range, mean winter precipitation, mean winter temperature, elevation range and mean elevation. For the 7 alpine and boreal heath models, the same covariates were used, except maximum elevation replaced mean elevation. Once the variables are selected, the individual models in BIOMOD use internal measurements, based on either stepwise regression or classification error rates; the Akaike's information criterion (AIC) statistic is also evaluated internally, and the model with the lowest AIC score is chosen. BIOMOD also provides an assessment of variable importance based on the extent to which model predictions change when a given variable is randomised (Thuiller et al. 2009).

To measure changes in climatic suitability for the habitats rather than interpreting model projections as estimates of the changes in observed habitat distributions, an unlimited habitat expansion scenario was adopted, whereby the habitats are assumed to be able to track shifting suitable climate over the entire study area. We recognise that this is unrealistic for habitat modelling in particular, but the choice reflects a desire to assess the potential change in the overall climate space for the focal heath habitats in Ireland. The null or full dispersal scenarios generally considered in most studies are considered a limitation of BEMs (e.g. Thuiller et al. 2008). However, newer methods developed for mobile species (e.g. Barbet-Massin et al. 2012) are not appropriate for habitat modelling. 


\subsection{Model predictive performance}

Projections of the probability of occurrence for each individual model were based on a threshold maximizing the true skill statistic (TSS), a commonly used threshold because it produces the most accurate predictions (Allouche et al. 2006). Model accuracy was also assessed with the area under the curve (AUC) from receiver operating characteristic plots (Fielding \& Bell 1997). Although AUC has been criticised recently (e.g. Lobo et al. 2008), it still provides an informative measure of model discriminatory performance (Reineking \& Schröder 2006). We also use Cohen's kappa as a further measure of model predictive performance and as a further measure widely applied in the literature.

Each individual model in BIOMOD assesses the contribution of the predictor variables to the model, and a permutation procedure enables the extraction of a measure of the relative importance of each variable. Following model calibration, a standard prediction is made; then, following randomisation of one of the variables, a new prediction is made. The correlation score between the standard and new prediction is calculated and is considered to give an estimation of the variable importance in the model (Thuiller et al. 2009).

By allowing the calculation of an ensemble prediction from all the models, the BIOMOD framework reduces the uncertainties arising from the use of only a single model. Several methods are provided to enable this, such as probability mean and weighted mean. A PCA of the median value was used and is calculated on the probabilities given by the models. This ranks the models according to their predictive performance, and in the version of BIOMOD used here, the consensus model is the model whose projection is the most closely correlated with the first axis of the PCA (Thuiller et al. 2009). It is considered to be more reliable because it is less influenced by extreme values (Thuiller et al. 2009), and a decay weighting of 1.6 was used. The decay gives the relative importance of the weights, e.g. a decay of 1 is equivalent to a committee averaging, whereby the same weights are given to all the elements.

\section{RESULTS}

\subsection{Model performance and the importance of variables}

The predicted baseline distributions obtained for all the BIOMOD wet heath models have good TSS values (0.648-0.713), kappa values (0.652-0.714) and AUC range of values (0.874-0.929) (Table 2). Similarly, the predicted baseline distributions obtained for all the BIOMOD alpine and boreal heath models have good TSS values (0.671-0.737) and good to excellent kappa values (0.670-0.738) and AUC range of values (0.858-0.936) (Table 2). This consistent performance between the models for the baseline is reflected in the mean predicted probability for each model type, which is not the case for the climate change projections, where there are substantial differences in the mean probabilities for both the wet heath (Fig. 2a) and alpine and boreal heath (Fig. 2b) models.

For the wet heath modelling, there is again consistency between the BIOMOD models in relation to the variable importance. Across the models, mean winter precipitation and mean elevation emerge as consistently important, although the relative importance of each varies between the models according to the influence of the other covariates in each individual model type (Fig. 3a). For the alpine and boreal heath models, while mean winter precipitation is also consistently the main climatic 
variable of importance, there is more variation in the importance of the topographic covariates in the models. Maximum elevation emerges as the topographic variable of greatest importance in the ANN, CTA, GBM and RF models, whereas elevation range is more important in the GAM, GLM and FDA models (Fig. 3b).

\subsection{Comparison of baseline and projected climate change}

\subsubsection{Wet heath models}

A comparison of the mapped predictions for the baseline period from the 7 BIOMOD models with the observed distribution indicates that the general pattern of the spatial distribution of wet heath is well captured in all models, with incorrect predictions mainly occurring in grid cells around the Midlands (Figs. S1-S7 in the Supplement, available at www.int-res.com suppl/c069p177_supp.pdf).

By contrast, when the A1B scenario climate change data are projected through the models, the results differ substantially between the different models. The GLM and FDA models project the greatest potential loss of climate space compared to the baseline (Table 3; Figs. S1 \& S7 in the Supplement). The GAM model projects substantial losses of climate space in the south but gains in the north (Table 3; Fig. S2 in the Supplement), while the ANN and GBM models project some loss of climate space in the south with gains in the north (Table 3; Figs. S3 \& S4 in the Supplement). The RF model projects considerable gains across the country (Table 3; Fig. S5 in the Supplement), with the CTA model projecting substantial fragmentation of climate space in the south and west but gains in the east and north (Table 3; Fig. S6 in the Supplement).

The BIOMOD ensemble projections indicate an overall loss of suitable climate space for wet heath, although a number of areas remain stable and some gains are also projected (Fig. 4a). Cells representing a limited expansion scenario (more realistic) and full expansion scenario (less realistic) are represented by blue squares and blue and green squares, respectively. The projected changes indicate the greatest loss of climate space to be in the south and west of the country; the most substantial losses are associated with low-elevation coastal cells and other low-elevation cells away from the mountains of the southwest and west. Overall, therefore, the models are projecting most losses of suitable climate space for low-lying southern and western cells, whereas they indicate some preservation of stable climate space for upland areas. The projected expansions of climate space are primarily in the Midlands, the east and the northeast. However, if a more realistic post hoc limited dispersal scenario is applied, whereby only gains associated with cells adjacent to the baseline distribution are counted, projected climate space gains are only realistic for 76 of the $10 \times 10 \mathrm{~km}$ cells relative to the baseline.

\subsubsection{Alpine and boreal heath models}

A comparison of the mapped predictions for the baseline period from the 7 BIOMOD models with the observed distribution indicates that the general pattern of the spatial distribution of alpine and boreal heath is well captured in all models, with incorrect predictions mainly occurring in grid cells around the north of the country (Figs. S1-S7 in the Supplement).

By contrast, when the A1B scenario climate change data are projected through the models, the results differ substantially between the different models. The GLM 
and FDA models project the greatest potential loss of climate space compared to the baseline (Table 3; Figs. S8 \& S14 in the Supplement). The GAM model projects substantial losses of climate space in the south but gains in the north (Table 3; Fig. S9 in the Supplement), while the ANN and GBM models project some loss of climate space in the south with gains in the north (Table 3; Figs. S10 \& S11 in the Supplement). The RF and CTA models project considerable gains across the country (Table 3; Figs. S12 \& S13 in the Supplement).

The BIOMOD ensemble projection indicates a fragmentary loss of suitable climate space for alpine and boreal heath in the south and west, although many areas remain stable and regional gains are projected for the northeast (Fig. 4b). Cells representing a limited expansion scenario (more realistic) and full expansion scenario (less realistic) are represented by blue squares and blue and green squares, respectively. Overall, therefore, the models are projecting most losses of suitable climate space for low-lying southern and western cells, whereas they indicate substantial preservation of suitable climate space for upland areas. The projected expansions of climate space are primarily in the east and northeast. However, applying the more realistic post hoc limited dispersal scenario, whereby only cells adjacent to the baseline distribution are counted, projected climate space gains are only realistic for 45 of the $10 \times 10 \mathrm{~km}$ cells relative to the baseline.

\section{DISCUSSION}

\subsection{Modelling current distribution}

Overall, the results here provide good climate-based models for the distribution of wet heath and alpine and boreal heath which relatively accurately replicate the observed baseline distribution of the habitats across Ireland. All of the BIOMOD models with the application of climatic-based variables are useful predictors of heath habitat distributions in Ireland. In general, macroclimate is the primary environmental control on the distribution of the heaths at the geographical scale modelled here. However, topographic variables represented in these models by elevation, through their influence on microclimate (i.e. temperature and precipitation), are also important variables.

Mean winter precipitation and elevation emerge as the key variables in all model categories, although their relative importance in relation to the other covariates varies between the model types and between the different heath habitats. For example, mean winter precipitation and mean elevation are the key variables of importance in the wet heath models, whereas elevation range and maximum elevation alongside mean winter precipitation are more important in the alpine and boreal heath models. Using elevation terms in the models supports results showing that the inclusion of topographical variables improves the predictive accuracy of models for similar habitats (Coll et al. 2011, 2013, 2014, 2016) and species of these habitats (Hodd et al. 2014) in Ireland. As climatic and topographical gradients are known to operate at different spatial scales, with the latter nested in the former (Bruun et al. 2006), the inclusion of the elevation data in this study therefore provides a more local component for all the models. Elevation range has been commonly used as a surrogate for environmental and climatic heterogeneity within grid cells in species richness modelling studies, as topographical heterogeneity compresses biotic communities into 
more constricted vertical spaces (e.g. Richerson \& Lum 1980, Currie 1991, Coblentz $\&$ Riitters 2004) and effectively mingles habitat types and species that are otherwise often widely spatially separated.

Precipitation and elevation (through its influence on temperature) are known key controls on the habitat distribution in the present, and their importance as covariates in the models here reflect other modelling work on the distribution of active blanket bog habitat in Ireland (Jones et al. 2006, Donnelly et al. 2008, Coll et al. 2011, 2014). Hence, the future changes in climate space projected for the habitats in response to the changes in temperature and precipitation make sense both biogeographically and topographically at the finer scale of analysis presented here for Ireland.

\subsection{Modelling the effect of climate change on heath distribution}

The projected reduction and re-alignment of climate space associated with the wet heath in the current study are inconsistent with suggestions that the habitat may not be sensitive to climate change. However, the work here is the first study undertaken at a finer spatial scale and with elevation terms incorporated in the BIOMOD model families. While there is a wide range of projected changes between the model families themselves, the overall model consensus is for a reduction and realignment of the available climate space.

Although the alpine and boreal heath models project a similarly wide range of changes in climate space between the model types, the stability of climate space as projected by the BIOMOD consensus model is more surprising. Our models indicate apparently less sensitivity for this habitat compared to the results for the wet heath, a result which is inconsistent with previous thinking, i.e. that these habitats are more sensitive to climate change than the wet heaths. Internationally important bryophyte species and communities are also considered vulnerable, while arctic-montane species are projected to see areas of suitable climate either shift northwards or contract to higher elevations (Hodd et al. 2014).

It is also surprising that the influence of the temperature terms was not more substantial in the models for both habitats. UK-based modelling, for example, indicates that combinations of temperature and precipitation variables were important in BEMs for blanket peat. For the UK, it was found that models which included measures of both hydrological conditions and maximum temperature provided a better fit to the mapped peat area than models based on hydrological variables alone (Clark et al. 2010). However, given the importance of the elevation terms in all the models, it is possible that these served as a proxy for some of the other seasonal temperature terms which could have been included. Certainly, the covariates used and the variable importance are analogous to results obtained previously using the same methods for active blanket bogs in Ireland (Coll et al. 2014). However, results here indicate that the heath habitats are potentially less sensitive than some of the other Irish habitat types modelled to date using similar methods (Coll et al. 2013, 2014).

\subsection{Limitations and assumptions of the methods}

The limitations and assumptions involved in using a $10 \times 10 \mathrm{~km}$ grid are recognised. The important controlling variables of topographic and environmental heterogeneity, for instance, will be lost at this resolution, together with important finescale microclimatic controls. Similarly, for model grids at this resolution, no account 
can be taken of the relative coherence or patchiness of heath habitats within individual grids where the community presence is recorded. An obvious but important point in relation to the heath communities is that projected changes in the climate space associated with the current distribution of wet heaths and alpine and boreal heaths are not the same as projecting changes in the actual distribution of the habitats over the next century. It has been suggested, for example, that wetland habitats occurring under similar conditions, even if not in a state of active growth, could well persist over decades or longer despite a reduction in climate space (Clark et al. 2010).

The BEMs presented here are based on derived statistical relationships between the known mapped distribution of heaths and climatic variables; it is unlikely that this mapped distribution represents heaths in an equilibrium state with current climate. Given historical and contemporary drivers of change, particularly grazing pressure and the use of burning, the distributions of Irish heaths are substantially modified. It is therefore possible that the calibrated baseline models do not fully capture the climate envelope reflecting sustainable conditions for the presence of heaths. Nevertheless, and despite the criticisms, BEMs and other models are providing a better understanding of the mechanisms by which species and ecosystems can be affected by climate change, and considerable improvements are being made rapidly in virtually all aspects of this emerging field (Bellard et al. 2012).

The final variables selected in the models reflect 2 primary properties of the climate (temperature and water) that are key factors affecting species and habitat distribution (e.g. Whittaker et al. 2007, Araújo et al. 2011). However, other important environmental information is omitted in the models. Therefore, the models could be refined by adding more topography and land cover variables; obvious candidates for the heath habitats would be further information on slope angle and aspect, which through their controls on light regimes influence evapotranspiration. For example, differences in light regimes between north- and south-facing aspects in temperate latitudes can produce differences in temperature equivalent to a move of $\sim 200 \mathrm{~km}$ north (Austin \& van Neill 2011) and lead to many differences in species composition, with, in particular, a higher diversity of bryophytes found on north-facing slopes (Hodd \& Sheehy Skeffington 2011a,b). It has also been widely reported that the influence of local topography may create critical climatic refugia that are important even in studies of very large areas (e.g. Ohlemüller et al. 2008, Coll 2010, Austin \& Van Neill 2011). Consequently, there is scope to incorporate more refined measures in future models which better capture the influence of topography in creating the conditions necessary for supporting heath formation. However, prior to and throughout the modelling process, we critically considered key assumptions and rigorously evaluated covariate selection based on the data available. Therefore, we consider that the results are presented in an appropriate conceptual context (sensu Araújo \& Peterson 2012).

\subsection{Implications of changing climate space for heath distributions}

The projected decline and fragmentation of the climate space associated with heath habitats would have significant implications for the ecology of these complex upland ecosystems and their associated plant and animal species. Seasonal drying, for example, may affect surface microtopography and hydrology; this in turn will influence the plant composition, particularly impacting key bryophyte species (Hodd \& Sheehy Skeffington 2011, Hodd et al. 2014) and habitat suitability for birds (Carrol 
et al. 2011, Renwick et al. 2012) and other species. Loss of unprotected high-quality upland habitats such as heaths will result in the direct loss of upland biodiversity by physical removal of the habitats and their associated species, while degradation may cause reduced species diversity and local extinction of rare or sensitive species (Scally et al. 2010). Such a climate change-driven degradation and loss may have secondary impacts on the biodiversity value of the remaining heath areas through increased isolation and fragmentation of the remaining habitat. Additionally, upland ecosystems provide a range of ecosystem services remote from their location, e.g. the regulation of downstream areas through the flow of water; hence, any degradation or loss of these habitats has ecosystem service implications for habitats and human communities away from the uplands themselves.

Degrading heaths will also have an impact on the wider structure and function of the uplands as the overall mosaic of habitat types respond to climate change. For example, drier and warmer summers may increase the frequency, size and severity of uncontrolled fires (Albertson et al. 2010), and drought effects may become more common later in the year (e.g. Cannell et al. 2004). This may have severe impacts in areas already subject to pressures such as overgrazing, inappropriate burning, and loss of vegetation cover combined with erosion of the peat or soil. Although fire is currently not common in alpine or boreal heaths, nor recommended for management, a drier climate may result in more fires from lower altitude spreading into this habitat. This would lead to scarring of upper slopes and a slow subsequent recovery, with a likely loss of dwarf shrub cover, the moss Racomitrium lanuginosum and specialised montane species, to be replaced by bare ground or the rush Juncus squarrosus and graminoid species. There is also likely to be a modified seasonal incidence of extreme weather such as high-intensity precipitation events (Matthews et al. 2016). A substantial impact for heathlands could be a modified fire seasonality, with more summer and autumn fires than is currently the case (Albertson et al. 2010), and direct burning of the peat itself during fires, with negative consequences for the seed bank. These impacts could be exacerbated by subsequent increased winter rainfall. These factors may combine to result in increased erosion of the peaty soils associated with the wet heaths and the sparse skeletal soils associated with montane heaths.

A loss of montane and wet heath habitats in Ireland would be detrimental to the conservation of these Annex I habitats in Europe as a whole, disproportionate to the area present in Ireland. Although the alpine and boreal heath does not cover large areas in Ireland, the highly oceanic character of the habitat here means that it represents a very different aspect of this vegetation than that present across more continental mountain areas. Therefore, it is important to make every effort to conserve these habitats and to identify and mitigate against any threats to their future survival. Based on results here, climate change could be a key potential future threat to these habitats.

\section{CONCLUSIONS AND IMPLICATIONS FOR FUTURE WORK}

Our results indicate that the distribution of wet heath habitats in Ireland is regionally sensitive to climate change, most notably for lower-lying areas in the south and west of the country. Increasing temperature and precipitation changes may reduce and fragment the area that is suitable for heath development. This could have major implications for the lowland wet heath distributions along the western Atlantic 
seaboard, where the projected losses are greatest. Offsetting these losses are climate space gains in the Midlands and the northeast and some retention of suitable climate space in upland areas in the south and west. The stability of climate space for alpine and boreal heath as projected by the BIOMOD consensus model is more surprising, as this habitat is considered more sensitive to climate change. In addition, the consensus model projects a substantial expansion of the potentially available climate space to the north and east. In summary, projected climate space losses (gains) from the BIOMOD consensus model are $-40.84 \%$ (limited expansion) and $-10.38 \%$ (full expansion) for wet heath and $-18.31 \%$ (limited expansion) and $+28.17 \%$ (full expansion) for alpine and boreal heath. However, areas which are projected to become suitable in the future would not necessarily ever be suitable for the growth of heath due to factors not included in the models, particularly geology and the presence of intensive agriculture, especially in the Midlands. These projected changes may proportionately affect both the lowland and upland heath communities, with important conservation policy implications.

Incorporating more detailed information into the BEMs can further improve confidence and reduce uncertainty in model estimates for the future distribution of Irish heaths. Specifically, information such as habitat type and species composition at a finer scale could better inform us on the status and type of heaths. Such an approach would require accurate survey data integrated at a finer spatial resolution alongside finer-meshed climate and climate change data. Other information, e.g. underlying drift, soil conditions, and slope angle and aspect, may improve model results. The distribution models presented here should be applicable to areas of wet and montane heath distribution outside Ireland, so long as data for the evaluation of the estimates are available.

Some attempt has been made to deal with uncertainty, at least in relation to differing results between the model categories, by providing the results from the individual BEMs implemented in the BIOMOD framework alongside the ensemble projection. Certainly, there is substantial variation in the results between the individual BEM types when the A1B scenario data are projected through the models. Although only the downscaled output from $1 \mathrm{GCM}$ and scenario has been used to project climate space changes here, the methods lend themselves to using different GCM and RCM outputs from a range of scenarios (e.g. Fronzek et al. 2011, Garcia et al. 2012) and from different sources (e.g. Fronzek et al. 2012) to better encapsulate uncertainty. Given the importance of mean winter precipitation in all the BEM model families, if a wetter or dryer model or scenario had been used from the ENSEMBLES RCMs, the results projected via the BEMs could have varied further. Work using the new representative concentration pathways (RCPs) and multiple GCMs show that projected species distributions exhibit broad differences, depending not only on emissions scenarios but also on GCMs (Goberville et al. 2015). This is not surprising, as climate models project future climate conditions at a coarser scale of resolution than the biological and environmental data used to calibrate BEMs (Pacifici et al. 2015). Nevertheless, future work on Irish habitat modelling would benefit from using combined multi-GCM and multi-RCP data to better consider potential trajectories and uncertainties in projected future distributions.

Overall, such an expanded framework would allow the identification of adaptation strategies that are robust (i.e. insensitive) to climate change uncertainties, and would allow more confidence in identifying and targeting vulnerable areas of heath habitat for priority conservation management measures. However, future 
research could integrate such a scenarios-impacts (top-down) approach alongside a vulnerability-thresholds (bottom-up) approach. Rather than trying to predict impacts through individual scenarios, such an integrated approach would help to better identify critical thresholds for climate change vulnerabilities alongside other drivers of change in these sensitive systems. Such refinements would also help inform best practice conservation management, whereby limited resources could be directed to areas coincident with healthy and functional heath communities and projected future climate suitability.

Acknowledgements. We thank the technical and scientific support staff at NPWS (Ireland) for supplying the GIS habitat maps for Irish priority habitats and species, Graham French at the National Biodiversity Network (UK) for supplying the GISenabled Irish Grid data and Steve Wilkinson at JNCC (UK) for the priority habitats and species database containing the Northern Ireland records. We also thank Ray McGrath and Tido Semmler at Met Éireann for providing the C4I climate change data. John Coll also thanks his ICARUS colleagues Rod Teck and Colin Holman for their input in processing the climate change data. David Bourke thanks the Royal Irish Academy for awarding a Mobility Grant which enabled his visit to Laboratoire d'Ecologie Alpine, CNRS and Université Joseph Fourier, Grenoble, France, to collaborate with Dr. Wilfried Thuiller and his team on the application of BIOMOD to undertake the climate change and biodiversity modelling. Without all of that team's goodwill, assistance and support, our progress in the methods developed here for Ireland would not have been possible. This research was supported by the Irish Environmental Protection Agency under grants 2007-CCRP-2.26 and 2010-CCRPDS-2.3. We also very much thank the 3 anonymous reviewers who provided valuable comment and edit suggestions on the original manuscript. 


\section{LITERATURE CITED}

Albertson K, Aylen J, Cavan G, McMorrow J (2010) Climate change and the future occurrence of moorland wildfires in the Peak District of the UK. Clim Res 45: $105-118$

Allouche O, Tsoar A, Kadmon R (2006) Assessing the accuracy of species distribution models: prevalence, kappa and the true skill statistic (TSS). J Appl Ecol 43: 1223-1232

Araújo MB, Guisan A (2006) Five (or so) challenges for species distribution modelling. J Biogeogr 33: 1677-1688

Araújo MB, Peterson AT (2012) Uses and misuses of bio - climatic envelope modelling. Ecology 93: 1527-1539

Araújo MB, Alagador D, Cabeza M, Nogues-Bravo D, Thuiller W (2011) Climate change threatens European conservation areas. Ecol Lett 14: 484-492

Austin MP (1987) Models for the analysis of species response to environmental gradients. Vegetatio 69: 35-45

AustinMP (2007) Species distribution models and ecological theory: a critical assessment and some possible new approaches. Ecol Model 200: 1-19

Austin MP, Van Niel KP (2011) Improving species distribution models for climate change studies: variable selection and scale. J Biogeogr 38: 1-8

Barbet-Massin M, Thuiller W, Jiguet F (2012) The fate of European breeding birds under climate, land-use and dispersal scenarios. Glob Change Biol 18: 881-890

Bellard C, Bertelsmeier C, Leadley P, Thuiller W, Courchamp F (2012) Impacts of climate change on the future of biodiversity. Ecol Lett 15: 365-377

Bellard C, Leclerc C, Leroy B, Bakkenes M, Veloz S, Thuiller W, Courchamp F (2014) Vulnerability of biodiversity hot - spots to global change. Glob Ecol Biogeogr 23: 1376-1386

Berry PM, Dawson TP, Harrison PA, Pearson RG (2002) Modelling potential impacts of climate change on the bioclimatic envelope of species in Britain and Ireland.

Glob Ecol Biogeogr 11: 453-462

Berry PM, Dawson TP, Harrison PA, Pearson R, Butt N (2003) The sensitivity and vulnerability of terrestrial habitats and species in Britain and Ireland to climate change. J Nat Conserv 11: 15-23

Berry PM, Harrison PA, Dawson TP, Walmsley CA (eds) (2005) Modelling natural resource response to climate change (MONARCH). A local approach: development of

a conceptual methodological framework for universal application. UKCIP, Oxford

Bruun HH, Moen J, Virtanen R, Grytnes JA, Oksanen L, Angerbjorn A (2006) Effects of altitude and topography on species richness of vascular plants, bryophytes and lichens in alpine communities. J Veg Sci 17: 37-46

Cannell MGR, Palutikof JP, Sparks TH (2004) Review of UK climate change indicators. Department for Environment, Food and Rural Affairs, London

Carroll MJ, Dennis P, Pearce-Higgins JW, Thomas CD (2011) Maintaining northern peatland ecosystems in a changing climate: effects of soil moisture, drainage and drain blocking on craneflies. Glob Change Biol 17: 2991-3001 
Clark JM, Gallego-Sala AV, Allott TEH, Chapman SJ and others (2010) Assessing the vulnerability of blanket peat to climate change using an ensemble of statistical bioclimatic envelope models. Clim Res 45: 131-150

Coblentz DD, Riitters KH (2004) Topographic controls on the regional-scale biodiversity of the south-western USA. J Biogeogr 31: 1125-1138

Coll J (2007) Local scale assessment of climate change and its impacts in the Highlands and Islands of Scotland. PhD thesis, UHI Millennium Institute/The Open University, Milton Keynes

Coll J (2010) Climate change and Europe's mountains. In: Price MF (ed) Europe's ecological backbone: recognising the true value of our mountains. EEA Rep No. 6/2010, European Environment Agency, Copenhagen, p 74-84

Coll J, Gibb SW, Price MF, McClatchey J, Harrison J (2010) Developing site scale projections of climate change in the Scottish Highlands. Clim Res 45: 71-85

Coll J, Bourke D, Sheehy Skeffington M, Sweeney JC, Gormally M (2011) Developing a predictive modelling capacity for a climate change-vulnerable blanket bog habitat: assessing 1961-1990 baseline relationships. Ir Geogr 44: $27-60$

Coll J, Bourke D, Gormally M, Sheehy Skeffington M, Sweeney J (2013) Climate change impacts on biodiversity in Ireland: projecting changes and informing adaptation measures. In: Winners and losers: climate change impacts on biodiversity in Ireland. CCRP Rep No. 19, Environmental Protection Agency, Wexford

Coll J, Bourke D, Sheehy Skeffington M, Gormally M, Sweeney J (2014) Projected loss of active blanket bogs in Ireland. Clim Res 59: 103-115

Coll J, Bourke D, Sheehy Skeffington M, Gormally M, Sweeney JC (2016) Projected loss of climate space for active blanket bog in Ireland. In: Rotherham I (ed) In the bog: the ecology, landscape, archaeology and heritage of peatlands conference, Sheffield, UK, September 3-5, 2014 (in press)

Crawford RMM (2005) Trees by the sea: advantages and disadvantages of oceanic climates. Proc R Ir Acad B 106: 129-139

Crawford RMM (2008). Plants at the margin: ecological limits and climate change. Cambridge University Press, Cambridge

Cross JR (2006) The potential natural vegetation of Ireland. Proc R Ir Acad B 106: $65-116$

Currie DJ (1991) Energy and large-scale patterns of animaland plant-species richness. Am Nat 137: 27-49

Donnelly A, Caffarra A, Albanito F, Jones M (2008) The impact of climate change on semi-natural ecosystems in Ireland. In: Sweeney J (ed) Climate change in Ireland: refining the impacts. Environmental Protection Agency, Dublin, p 132-159

Dormann CF (2007) Promising the future? Global change projections of species distributions. Basic Appl Ecol 8: 387-397

Dormann CF, Elith J, Bacher S, Buchmann C and others (2013) Collinearity: a review of methods to deal with it and a simulation study evaluating their performance. Ecography 36: 27-46

EU (European Union) (2013) Interpretation manual of European Union habitats-EUR 28. European Commission, Brussels

Fagúndez J (2013) Heathlands confronting global change: drivers of biodiversity loss from past to future scenarios. Ann Bot 111: 151-172

Fielding A, Bell JF (1997) A review of methods for the assessment of prediction errors in conservation presence/ absence models. Environ Conserv 24: 38-49 
Fossitt JA (2000) A guide to habitats in Ireland. The Heritage Council, Dublin (reprint 2007)

Fronzek S, Luoto M, Carter TR (2006) Potential effect of climate change on the distribution of palsa mires in subarctic Fennoscandia. Clim Res 32: 1-12

Fronzek S, Carter TR, Luoto M (2011) Evaluating sources of uncertainty in modelling the impact of probabilistic climate change on sub-arctic palsa mires. Nat Hazards

Earth Syst Sci 11: 2981-2995

Fronzek S, Carter TR, Jylhä K (2012) Representing two centuries of past and future climate for assessing risks to biodiversity in Europe. Glob Ecol Biogeogr 21: $19-35$

Garcia RA, Burgess ND, Cabeza M, Rahbek C, Araújo MB (2012) Exploring consensus in 21st century projections of climatically suitable areas for African vertebrates. Glob Change Biol 18: 1253-1269

Goberville E, Beaugrand G, Hautekèete NC, Piquot Y, Luczak C (2015) Uncertainties in the projection of species distributions related to general circulation models. Ecol Evol 5: 1100-1116

Grenouillet G, Buisson L, Casajus N, Lek S (2011) Ensemble modelling of species distribution: the effects of geographical and environmental ranges. Ecography 34: 9-17

Guisan A, ThuillerW(2005) Predicting species distributions: offering more than simple habitat models. Ecol Lett 8: 993-1009

Guisan A, Edwards TC, Hastie T (2002) Generalized linear and generalized additive models in studies of species distributions: setting the scene. Ecol Model 157: $89-100$

Hampton M (2008) Management of Natura 2000 habitats. 4010 northern Atlantic wet heaths with Erica tetralix. European Commission, Brussels

Hastie T, Tibshirani R (1990) Generalized additive models. Chapman and Hall, London

Heikkinen RK, Luoto M, Araújo MB, Virkalla M, Thuiler W, Sykes MT (2006) Methods and uncertainties in bioclimatic envelope modelling under climate change. Prog Phys Geogr 30: 751-777

Hodd RL, Sheehy Skeffington MJ (2011a) Climate change and oceanic montane vegetation: a case study of the montane heath and associated plant communities in western Irish mountains. In: Hodkinson T, Jones M, Waldren

S, Parnell J (eds) Climate change, ecology and systematics. Cambridge University Press, Cambridge

Hodd RL, Sheehy Skeffington MJ (2011b) Mixed northern hepatic mat: a threatened and unique bryophyte community. Field Bryol 104: 2-11

Hodd RL, Bourke D, Sheehy Skeffington MJ (2014) Projected range contractions of European protected oceanic montane plant communities: focus on climate change

impacts is essential for their future conservation. PLOS ONE 9: e95147

Holden J, Shotbolt L, Bonn A, Burt TP and others (2007) Environmental change in moorland landscapes. Earth Sci Rev 82: 75-100

Jacob D, Christensen OB, Doblas-Reyes FJ, Goodess C, Klein Tank A, Lorenz P, Roeckner E (2008) Information on observations, global and regional modelling data availability and statistical downscaling. ENSEMBLES Tech Rep No. 4, Sixth Framework Programme, European Commission. Available at: http://ensembles-eu.metoffice. com/tech_reports/ETR_4_vn1.pdf (accessed Oct 2013) 
JNCC (Joint Nature Conservation Committee) (2007) Second report by the UK under Article 17 on the implementation of the Habitats Directive from January 2001 to December 2006. JNCC, Peterborough

Jones MB, Donnelly A, Albanito F (2006) Responses of Irish vegetation to future climate change. Biol Environ 106B: 323-334

Kirschbaum MUF (2000) Will changes in soil organic carbon act as a positive or negative feedback on global warming? Biogeochemistry 48: 21-51

Lobo JM, Jimenez-Valverde A, Real R (2008) AUC: a misleading measure of the performance of predictive distribution models. Glob Ecol Biogeogr 17: 145-151

Marmion M, Luoto M, Heikkinen RK, Thuiller W (2009a) The performance of stateof-the-art modelling techniques depends on geographical distribution of species. Ecol Model 220: 3512-3520

Marmion M, Parviainen M, Luoto M, Heikkinen R, Thuiller W(2009b) Evaluation of consensus methods in predictive species distribution modelling. Divers Distrib 15: $59-69$

Matthews T, Mullan D, Wilby RL, Broderick C, Murphy C (2016) Past and future climate change in the context of memorable seasonal extremes. Clim Risk Manage 11: 37-52

McCullagh P, Nelder J (1989) Generalized linear models. Chapman and Hall, London

McGrath R, Lynch P (eds) (2008) Ireland in a warmer world: scientific predictions of the Irish climate in the twentyfirst century. Community Climate Change Consortium for Ireland (C4I), Dublin

NPWS (National Parks and Wildlife Service) (2008) The status of EU protected habitats and species in Ireland. NPWS, Department of the Environment, Heritage and Local Government, Dublin

Ohlemüller R, Anderson BJ, Araújo MB, Butchart SHM, Kudrna OR, Ridgely RS, Thomas CD (2008) The coincidence of climatic and species rarity: high risk to small range species from climate change. Biol Lett 4: 568-572

Orme CDL, Davies RG, Burgess M, Eigenbrod F and others (2005) Global hotspots of species richness are not congruent with endemism or threat. Nature 436: $1016-1019$

Pacifici M, Foden WB, Visconti P, Watson JEM and others (2015) Assessing species vulnerability to climate change. Nat Clim Change 5: 215-225

Parviainen M, Luoto M (2007) Climate envelopes of mire complex types in Fennoscandia. Geogr Ann Ser A 89: 137-151

Pearce J, Ferrier S (2000) Evaluating the predictive performance of habitat models developed using logistic regression. Ecol Model 133: 225-245

Peñuelas J, Gordon C, Llorens L, Nielsen T and others (2004) Non-intrusive field experiments show different plant responses to warming and drought among sites, seasons, and species in a north-south European gradient. Ecosystems 7: 598-612

Pepin N, Bradley RS, Diaz HF, Baraer M and others (2015) Elevation-dependent warming in mountain regions of the world. Nat Clim Change 5: 424-430

Perrin PM, Barron SJ, Roche JR, O'Hanrahan B (2014) Guidelines for a national survey and conservation assessment of upland vegetation and habitats in Ireland. Version 2.0. Irish Wildlife Manuals No. 79. National Parks and Wildlife Service, Department of Arts, Heritage and the Gaeltacht, Dublin

R Development Core Team (2014) CRAN R library repository. Available at: http: //cran.r-project.org/

Reineking B, Schröder B (2006) Constrain to perform: regularization of habitat models. Ecol Model 193: 675-690 
Renwick AR, Massimino D, Newson SE, Chamberlain DE, Pearce-Higgins JW, Johnston A (2012) Modelling changes in species' abundance in response to projected climate change. Divers Distrib 18: 121-132

Richerson PJ, Lum KL (1980) Patterns of plant species diversity in California: relation to weather and topography. Am Nat 116: 504-536

Ricketts TH, Dinerstein E, Boucher T, Brooks TM and others (2005) Pinpointing and preventing imminent extinctions. Proc Natl Acad Sci USA 102: 18497-18501

Rohan PK (1986) The climate of Ireland. The Stationery Office, Dublin

Ross L 2015. Climate change impacts on the vegetation of Ben Lawers. Scottish Natural Heritage Commissioned Rep No. 879, Scottish Natural Heritage, Inverness

Ross LC, Woodin SJ, Hester AJ, Thompson DBA, Birks HJB (2012) Biotic homogenization of upland vegetation: patterns and drivers at multiple spatial scales over five decades. J Veg Sci 23: 755-770

Scally L, Waldren S, Atalah J, Brown M and others (2010) BioChange-biodiversity and environmental change: an integrated study encompassing a range of scales, taxa and habitats. Draft Tech Proj Rep, Environmental Protection Agency, Wexford

Schroder B, Seppelt R (2006) Analysis of pattern-process interactions based on landscape models - overview, general concepts, and methodological issues. Ecol Model 199: 505-516

Segurado P, Araújo MB (2004) An evaluation of methods for modelling species distributions. J Biogeogr 31: 1555-1568

Sweeney J, Fealy R (2003) Establishing reference climate scenarios. In: Sweeney J (ed) Climate change scenarios and impacts for Ireland. ERTRI Rep 15, Environmental Protection Agency, Dublin

Sweeney K, Fealy R, McElwain L, Siggins L, Sweeney J, Trinies T (2008) Changing shades of green: the environmental and cultural impacts of climate change in Ireland. The Irish American Climate Project \& Rockefeller Family Fund, New York, NY

Thuiller W (2003) BIOMOD-optimizing predictions of species distributions and projecting potential future shifts under global change. Glob Change Biol 9: $1353-1362$

Thuiller W (2004a) Patterns and uncertainties of species' range shifts under climate change. Glob Change Biol 10: 2020-2027

Thuiller W (2014) Editorial commentary on 'Patterns and uncertainties of species' range shifts under climate change'. Glob Change Biol 20: 3593-3594

Thuiller W, Araújo MB, Lavorel S (2004b) Do we need landcover data to predict species distributions in Europe? J Biogeogr 31: 353-361

Thuiller W, Broennimann O, Hughes GO, Alkemade JMR, Midgley GF, Corsi F (2006) Vulnerability of African mammals to anthropogenic climate change under conservative land transformation assumptions. Glob Change Biol 12: 424-440

Thuiller W, Albert C, Araújo MB, Berry PM and others (2008) Predicting global change impacts on plant species' distributions: future challenges. Perspect Plant Ecol Evol Syst 9: 137-152

Thuiller W, Lafourcade B, Araújo M (2009) Model operating manual for BIOMOD. Universite Joseph Fourier, Grenoble

van der Linden P, Mitchell JFB (eds) (2009) ENSEMBLES: climate change and its impacts: summary of research and results from the ENSEMBLES project. Met Office Hadley Centre, Exeter 
Vaughan IP, Ormerod SJ (2005) The continuing challenges of testing species distribution models. J Appl Ecol 42: 720-730

Whittaker RJ, Nogues-Bravo D, Araújo MB (2007) Geographic gradients of species richness: a test of the water energy conjecture of Hawkins et al. (2003) using European data for five taxa. Glob Ecol Biogeogr 16: 76-89

Zaghi D (2008) Management of Natura 2000 habitats. 4060 alpine and boreal heaths. European Commission, Brussels. 

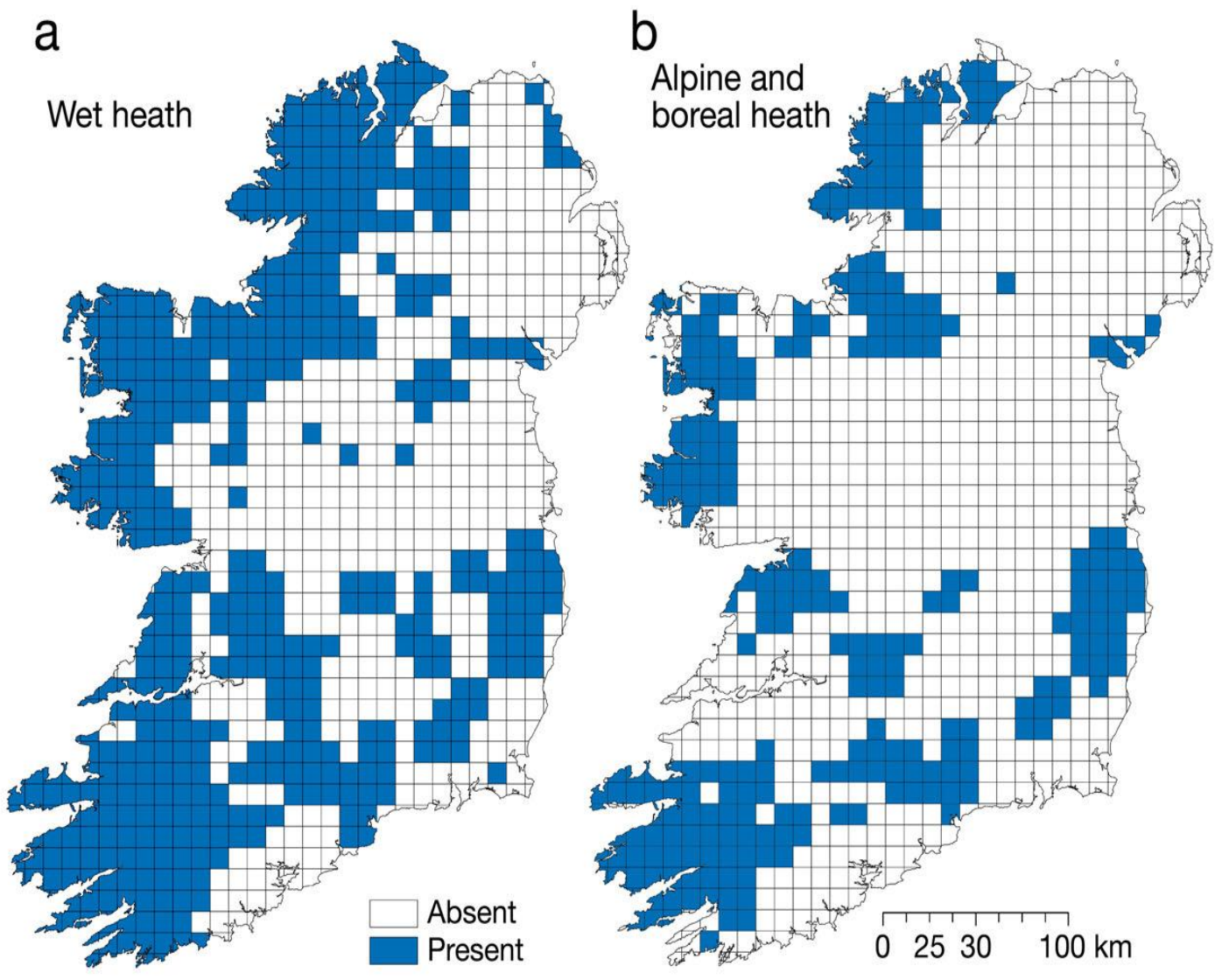

Fig. 1. Current distribution of (a) wet heath and (b) alpine and boreal heath in Ireland. Blue squares denote the habitat presence; white squares denote absence. The map is based on National Parks and Wildlife Service data (Ireland) and Joint Nature Conservancy Council data (Northern Ireland) 


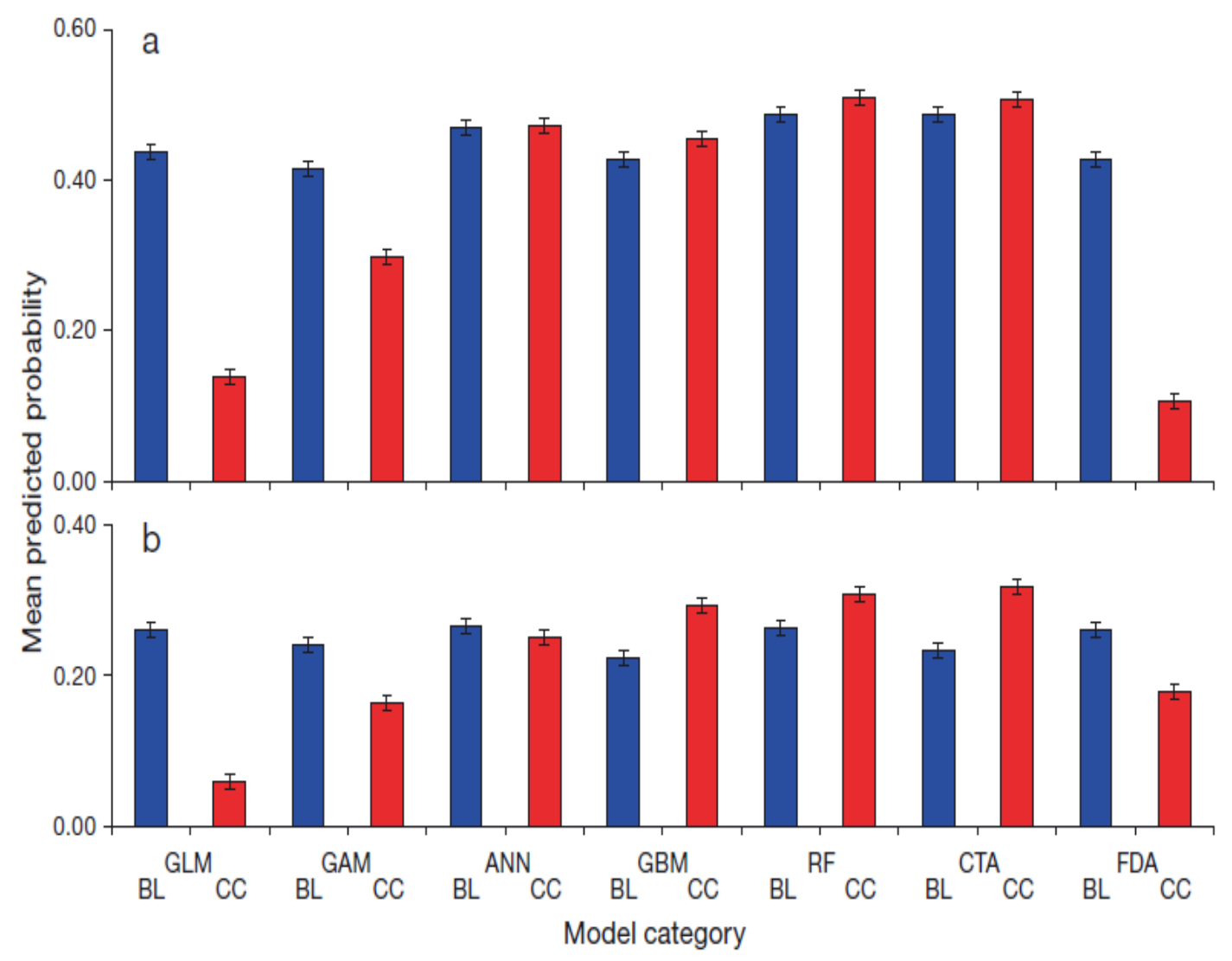

Fig. 2. Comparison of the predictive performance of the 7 models implemented in BIOMOD illustrating the mean probability distribution shifts associated with climate change projections compared to the baseline for (a) wet heath and (b) alpine and boreal habitats. BL (blue) denotes the 1961-1990 baseline prediction for each model type; CC (red) denotes the 2031-2060 climate change projection for each model type. Error bars: SE. GLM: generalised linear model; GAM: generalised additive model; ANN: artificial neural network; GBM: generalised boosting method; RF: random forest; CTA: classification tree analysis; FDA: flexible discriminant analysis 


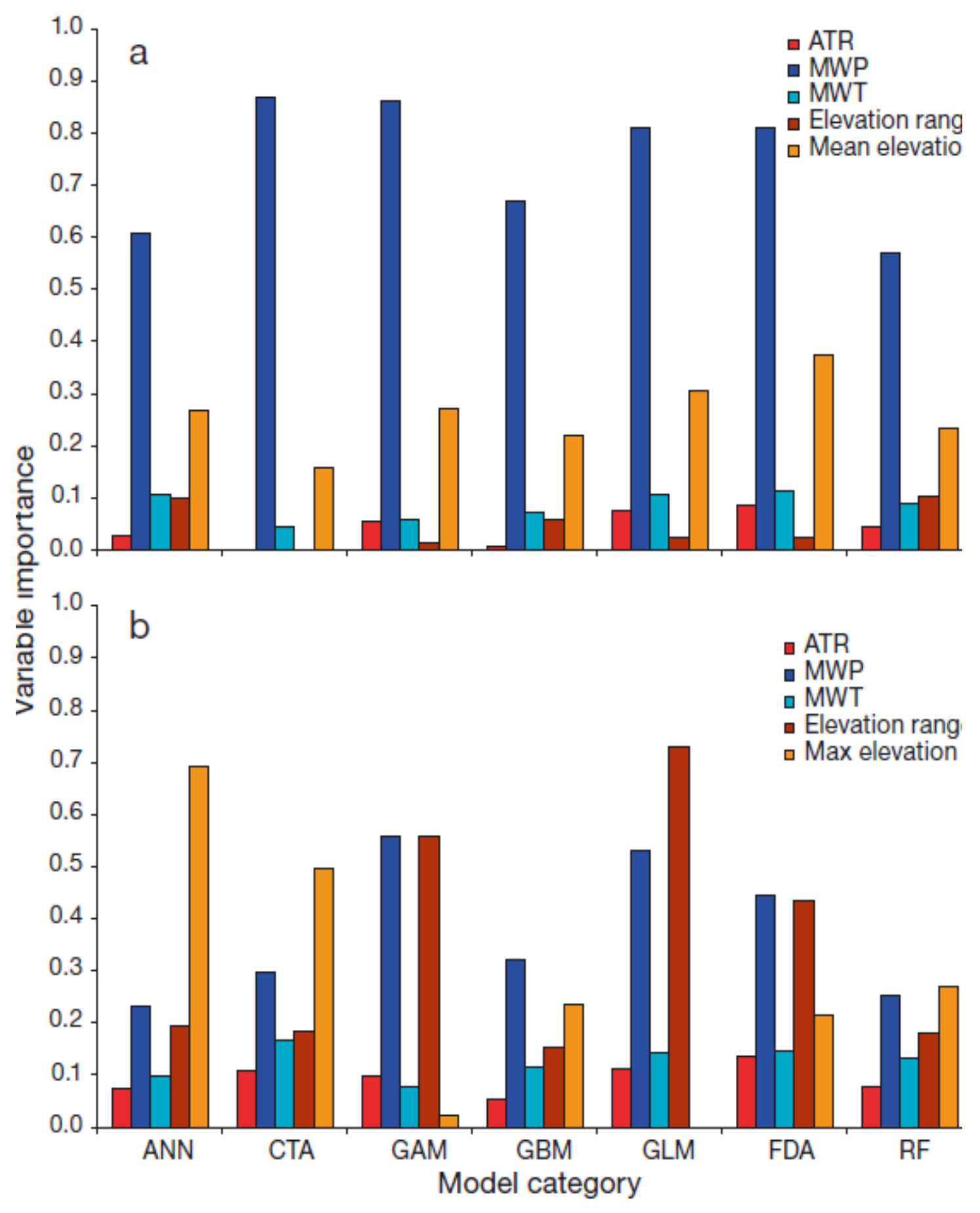

Fig. 3. Relative importance of the variables used to model (a) wet heath and (b) alpine and boreal habitats. The variable of importance was calculated as 1 minus the correlation between the standard prediction and the prediction where the considered variable was randomised. ATR: annual temperature range; MWP: mean winter precipitation; MWT: mean winter temperature; Range: elevation range; Mean: mean elevation. ANN: artificial neural network; CTA: classification tree analysis; GAM: generalised additive model; GBM: generalised boosting method; GLM: generalised linear model; FDA: flexible discriminant analysis; RF: random forest 


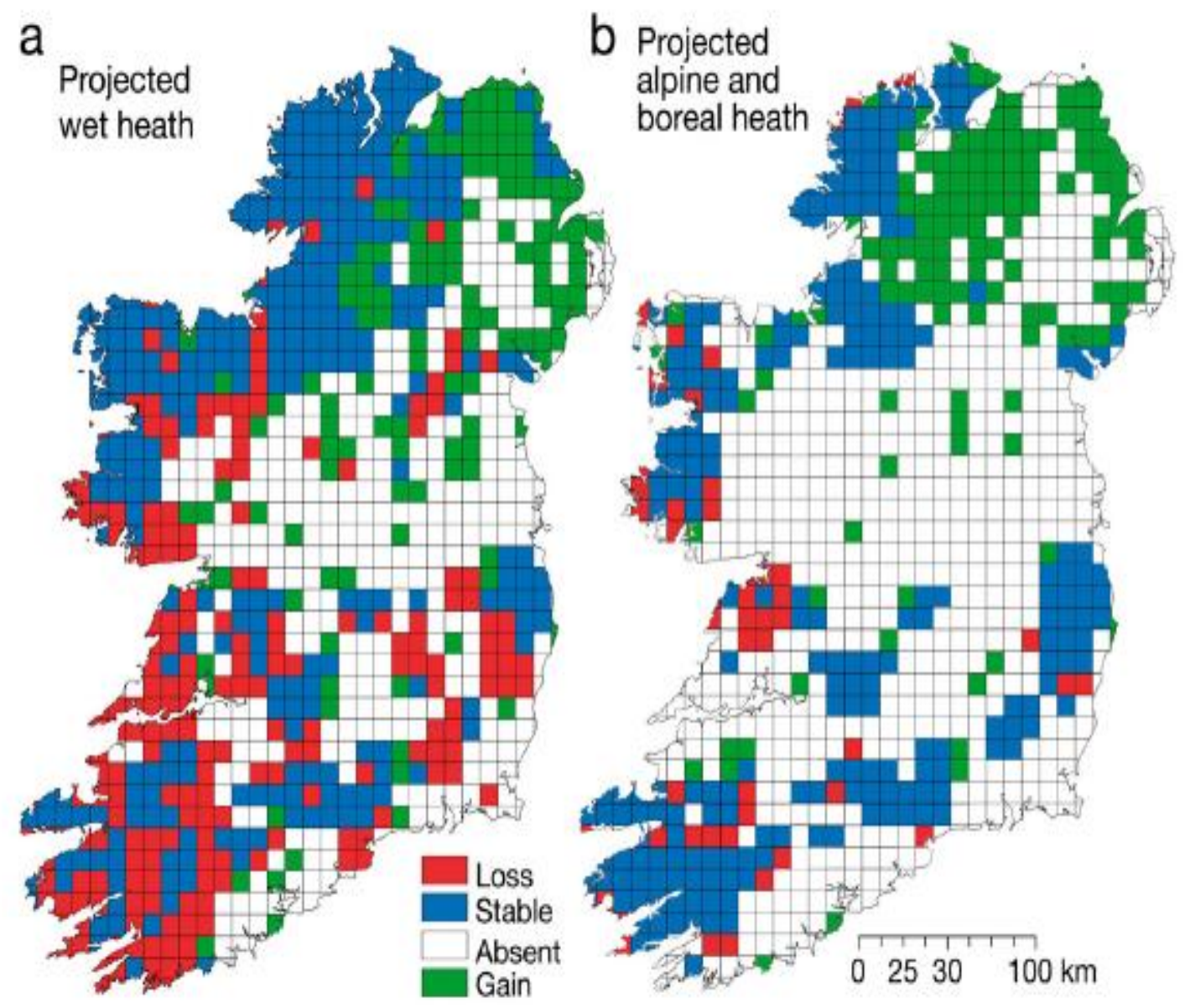

Fig. 4. Mapped BIOMOD consensus model outputs for (a) wet heath and (b) alpine and boreal heath habitats based on median probability ensemble forecasting method values using the true skill statistic threshold. Red squares denote projected losses of climate space for the A1B 2031-2060 scenario relative to the baseline; blue squares denote stable climate space grids (areas of suitable climate under a no dispersal - no habitat expansion - scenario); green squares denote potential climate space gains relative to the baseline; blue and green squares combined indicate areas of suitable climate under a full dispersal (habitat expansion) scenario 
Table 1. Covariate selection evaluated for inclusion in the 7 bioclimatic envelope models

\begin{tabular}{llc}
\hline Name & Definition & Unit \\
\hline Climate & Annual temperature range (maximum temperature of & \\
ATR & warmest month-minimum temperature of the coldest month) & ${ }^{\circ} \mathrm{C}$ \\
& ${ }^{\circ} \mathrm{C}$ \\
MAT & Mean annual temperature & ${ }^{\circ} \mathrm{C}$ \\
MST & Mean summer temperature & ${ }^{\circ} \mathrm{C}$ \\
MTW & Mean temperature of warmest month & ${ }^{\circ} \mathrm{C}$ \\
MWT & Mean winter temperature & $\mathrm{mm}$ \\
NAP & Net annual precipitation & $\mathrm{mm}$ \\
MSP & Mean summer precipitation (June-August) & $\mathrm{mm}$ \\
MWP & Mean winter precipitation (December-February) & \\
& & \\
Topography & & $\mathrm{m}$ \\
Min & Minimum elevation & $\mathrm{m}$ \\
Max & Maximum elevation & $\mathrm{m}$ \\
Mean & Mean elevation & $\mathrm{m}$ \\
Range & Elevation range \\
\hline
\end{tabular}

Table 2. Summary comparison of model evaluation statistics with respect to the 7 BIOMOD modelling techniques used for wet heath and alpine and boreal habitats. TSS: true skill statistic; Kappa: Cohen's kappa; AUC: area under the curve. GLM: generalised linear model; GAM: generalised additive model; ANN: artificial neural network; GBM: general boosting method; RF: random forest; CTA: classification tree analysis; FDA: flexible discriminant analysis

\begin{tabular}{llcl}
\hline Model category & TSS & Kappa & AUC \\
\hline Wet heath & & & \\
GLM & 0.694 & 0.691 & 0.916 \\
GAM & 0.690 & 0.687 & 0.919 \\
ANN & 0.648 & 0.652 & 0.900 \\
GBM & 0.713 & 0.711 & 0.929 \\
RF & 0.712 & 0.714 & 0.929 \\
CTA & 0.671 & 0.674 & 0.874 \\
FDA & 0.706 & 0.705 & 0.918 \\
CONSENSUS & 0.691 & 0.691 & 0.912 \\
& & & \\
Alpine and boreal heath & & & 0.920 \\
GLM & 0.683 & 0.670 & 0.921 \\
GAM & 0.692 & 0.683 & 0.890 \\
ANN & 0.671 & 0.641 & 0.936 \\
GBM & 0.737 & 0.738 & 0.933 \\
RF & 0.721 & 0.710 & 0.858 \\
CTA & 0.666 & 0.678 & 0.914 \\
FDA & 0.671 & 0.695 & 0.910 \\
CONSENSUS & 0.692 & 0.688 & \\
\hline
\end{tabular}


Table 3. Summary comparison of individual model baseline prediction calls and projected changes in climate space associated with the A1B 2031-2060 climate scenario data applied for each $10 \times 10 \mathrm{~km}$ grid square for the wet heath habitat. GLM: generalised linear model; GAM: generalised additive model; ANN: artificial neural network; GBM: general boosting method; RF: random forest; CTA: classification tree analysis; FDA: flexible discriminant analysis. See Table 1 for acronyms

\begin{tabular}{|c|c|c|c|c|c|c|c|c|}
\hline $\begin{array}{l}\text { Model } \\
\text { category }\end{array}$ & $\begin{array}{l}\text { Baseline } \\
\text { predicted } \\
\text { presence }\end{array}$ & $\begin{array}{l}\text { Baseline } \\
\text { predicted } \\
\text { absence }\end{array}$ & $\begin{array}{l}\text { Climate } \\
\text { change } \\
\text { projected } \\
\text { presence }\end{array}$ & $\begin{array}{l}\text { Climate } \\
\text { change } \\
\text { projected } \\
\text { absence }\end{array}$ & $\begin{array}{l}\text { Projected } \\
\text { loss }\end{array}$ & $\begin{array}{l}\text { Projected } \\
\text { stable }\end{array}$ & $\begin{array}{l}\text { Projected } \\
\text { gain }\end{array}$ & $\begin{array}{l}\text { Change } \\
\text { from } \\
\text { baseline }(\%)\end{array}$ \\
\hline \multicolumn{9}{|c|}{ Wet heath } \\
\hline GLM & 478 & 485 & 154 & 809 & 394 & 499 & 70 & -67.8 \\
\hline GAM & 453 & 510 & 319 & 644 & 249 & 599 & 115 & -29.6 \\
\hline ANN & 522 & 441 & 525 & 438 & 154 & 652 & 157 & +0.6 \\
\hline GBM & 482 & 481 & 535 & 428 & 104 & 702 & 157 & +9.0 \\
\hline RF & 284 & 679 & 648 & 315 & 9 & 581 & 373 & +56.2 \\
\hline CTA & 504 & 459 & 510 & 453 & 178 & 601 & 184 & +1.0 \\
\hline FDA & 460 & 503 & 116 & 847 & 399 & 509 & 55 & -74.8 \\
\hline \multicolumn{9}{|c|}{$\begin{array}{l}\text { Alpine and } \\
\text { boreal heath }\end{array}$} \\
\hline GLM & 367 & 596 & 90 & 873 & 308 & 624 & 31 & -74.5 \\
\hline GAM & 318 & 645 & 225 & 738 & 157 & 742 & 64 & -29.3 \\
\hline ANN & 384 & 579 & 334 & 629 & 95 & 823 & 45 & -13.1 \\
\hline GBM & 277 & 686 & 344 & 619 & 30 & 836 & 97 & +19.5 \\
\hline $\mathrm{RF}$ & 284 & 679 & 374 & 589 & 43 & 787 & 133 & +24.1 \\
\hline CTA & 244 & 719 & 333 & 630 & 10 & 854 & 99 & +16.7 \\
\hline FDA & 347 & 616 & 187 & 776 & 205 & 713 & 45 & -46.2 \\
\hline
\end{tabular}

